JOURNAL OF

SYNCHROTRON

RADIATION

ISSN 1600-5775

Received 13 February 2019

Accepted 19 May 2019

Edited by I. Lindau, SLAC/Stanford University, USA

₹ Present address: National Synchrotron Light Source (NSLS-II), Brookhaven National Laboratory, Upton, NY 11973, USA. $\S$ Present address: Department of Materials Science and Engineering, Northwestern University, Evanston, IL 60208, USA. - Present address: Korea Institute of Science and Technology (KIST), Seoul, Korea.

Keywords: atomic layer deposition; electrode architectures; pair distribution functions; high-energy X-ray scattering; catalysts; electrochemistry; ultra-thin films.

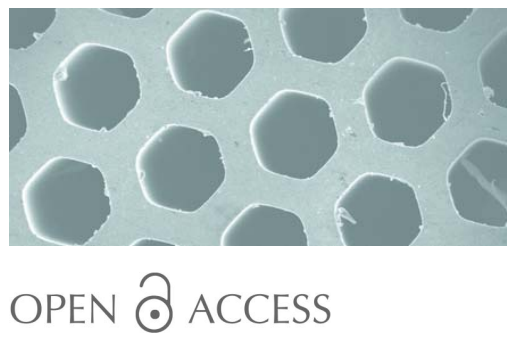

\section{Microfluidic electrochemical cell for in situ structural characterization of amorphous thin-film catalysts using high-energy X-ray scattering}

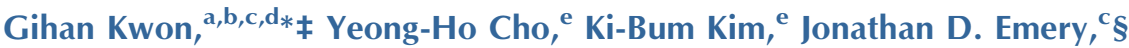 \\ In Soo Kim, ${ }^{c}$ Xiaoyi Zhang, ${ }^{f}$ Alex B. F. Martinson ${ }^{c}$ and David M. Tiede ${ }^{d_{*}}$
}

\begin{abstract}
aArgonne Northwestern Solar Energy Research (ANSER) Center, Northwestern University, 2145 Sheridan Road, Tech Room L110, Evanston, IL 60208-3113, USA, borthwestern-Argonne Institute of Science and Engineering, Northwestern University, 2205 Tech Drive, Evanston, IL 60208, USA, '⿳M Materials Science Division, Argonne National Laboratory, 9700 South Cass Ave, Lemont, IL 60439, USA, ${ }^{\mathbf{d} C h e m i c a l ~ S c i e n c e s ~ a n d ~ E n g i n e e r i n g ~ D i v i s i o n, ~ A r g o n n e ~ N a t i o n a l ~}$ Laboratory, 9700 South Cass Ave, Lemont, IL 60439, USA, ${ }^{\mathbf{e}}$ Nano Fabrication Laboratory, Research Institute of Advanced Materials, Department of Materials Science and Engineering, Seoul National University, 599 Gwanak-ro, Gwanak-gu 151-744, South Korea, and ' X-ray Science Division, Argonne National Laboratory, 9700 South Cass Ave, Lemont, IL 60439, USA. *Correspondence e-mail: gkwon@bnl.gov, tiede@anl.gov
\end{abstract}

Porous, high-surface-area electrode architectures are described that allow structural characterization of interfacial amorphous thin films with high spatial resolution under device-relevant functional electrochemical conditions using high-energy X-ray ( $>50 \mathrm{keV})$ scattering and pair distribution function (PDF) analysis. Porous electrodes were fabricated from glass-capillary array membranes coated with conformal transparent conductive oxide layers, consisting of either a $40 \mathrm{~nm}-50 \mathrm{~nm}$ crystalline indium tin oxide or a $100 \mathrm{~nm}-$ $150 \mathrm{~nm}$-thick amorphous indium zinc oxide deposited by atomic layer deposition. These porous electrodes solve the problem of insufficient interaction volumes for catalyst thin films in two-dimensional working electrode designs and provide sufficiently low scattering backgrounds to enable high-resolution signal collection from interfacial thin-film catalysts. For example, PDF measurements were readily obtained with $0.2 \AA$ spatial resolution for amorphous cobalt oxide films with thicknesses down to $60 \mathrm{~nm}$ when deposited on a porous electrode with $40 \mu \mathrm{m}$-diameter pores. This level of resolution resolves the cobaltate domain size and structure, the presence of defect sites assigned to the domain edges, and the changes in fine structure upon redox state change that are relevant to quantitative structure-function modeling. The results suggest the opportunity to leverage the porous, electrode architectures for PDF analysis of nanometrescale surface-supported molecular catalysts. In addition, a compact 3D-printed electrochemical cell in a three-electrode configuration is described which is designed to allow for simultaneous X-ray transmission and electrolyte flow through the porous working electrode.

\section{Introduction}

In situ structural characterization of ultra-thin electrochemically active materials with atomic scale resolution is required to achieve an understanding of the reaction mechanisms and for the design of new materials. The resolution of structure during electrochemical and catalytic function is important for a range of electrochemical energy storage (Wiaderek et al., 2013), electrocatalysis (Danilovic et al., 2014; Ocko et al., 1990; Tidswell et al., 1993; Ingham et al., 2008) and solar photoelectrochemical (Reece et al., 2011; Nocera, 2012) applications.

The extensive literature describes electrochemical cell designs for in situ characterization of interfacial electro- 
chemistry using a variety of X-ray techniques, including X-ray absorption fine-structure (XAFS) spectroscopy (Merte et al., 2012; Virtanen, 2002; Watanabe et al., 2007; Kordesch \& Hoffman, 1984), X-ray reflectivity, standing wave, diffraction (Veder et al., 2011; Wang et al., 1992; Tidswell et al., 1993; Ingham et al., 2008; Renner et al., 2007; Robinson \& O'Grady, 1993; Koop et al., 1998; Morcrette et al., 2002; Tamura et al., 2002) and high-energy X-ray scattering (HEXS) (Borkiewicz et al., 2012; Jensen et al., 2015). XAFS data collection in the fluorescence mode has proven to be a sensitive and well suited technique for interrogating metal-atom oxidation states and the electronic and coordination structures of interfacial thin-film catalysts (Risch et al., 2015, 2012; Kanan et al., 2010). XAFS provides an accurate measure of metal-to-ligand atom distances within the inner-coordination shell. However, information on atom pair distances with outer-shell coordination $(4 \AA-10 \AA)$ and longer-range structures are typically limited in XAFS measurements for disordered, amorphous, molecular and non-crystalline materials (Du et al., 2012; Blakemore et al., 2013; Mulfort et al., 2013; Yang et al., 2016). X-ray scattering techniques provide a complementary measure of the outer shell and longer-range atomic order across the $1 \AA$ to $100 \mathrm{~nm}$ distance range (Mulfort et al., 2013; Blakemore et al., 2013). Grazing-incidence X-ray scattering techniques are widely employed for interfacial thin-film characterization, but are typically implemented with X-ray energies of less than $30 \mathrm{keV}$, which limits spatial resolution to $0.1 \mathrm{~nm}$ because of the shorter momentum transfer $(q)$.

HEXS and atomic pair distribution function (PDF) techniques are well suited for structural characterization of functional materials with sub-angstrom spatial resolution (Billinge \& Kanatzidis, 2004; Juhás et al., 2006; Billinge \& Levin, 2007; Michel et al., 2007; Chupas et al., 2009). PDF measurements achieve spatial resolution comparable to XAFS, and the two techniques complement each other to provide high-resolution structure characterization across the full-length scale from inner-shell metal coordination to intermediate-range distances (Németh et al., 2012; Mulfort et al., 2013; Blakemore et al., 2013; Yang et al., 2016). However, a challenge in applying PDF methods with high spatial resolution for the analysis of ultrathin films arises from the reduced atomic scattering crosssections for HEXS and the small interaction volume within ultra-thin films which limit the amplitude of scattering signals. PDF techniques have been developed that allow operando measurements of the structures of micrometre-scale electrode materials during electrochemical cycling in battery devices (Jung et al., 2015; Borkiewicz et al., 2012, 2015; Wiaderek et al., 2013). The use of high-flux synchrotron sources for HEXS and PDF analysis of sub-micrometre films on planar glass supports has been demonstrated through the resolution of the PDF for amorphous thin films of $\mathrm{FeSb}_{3}$ having a thickness of $360 \mathrm{~nm}$ (Jensen et al., 2015), although the thin glass support did not allow for electrochemical addressing of the supported film (Jensen et al., 2015). Furthermore, the sensitivity of HEXS to $\mathrm{FeSb}_{3}$ thin films is enhanced by more than a factor of ten compared with comparable oxide films. With the development of micro-focusing optics for high-energy X-rays, recent work has demonstrated high-resolution PDF measurements for surface-supported films of $\mathrm{ZrO}_{2}, \mathrm{HfO}_{2}$ (Dippel et al., 2019) and $\mathrm{Pt}$ (Roelsgaard et al., 2019) supported films that are a few nanometres thick using grazing-incidence HEXS.

In this report, we describe an alternate strategy for PDF analysis of thin-film transition-metal oxides by introducing a $3 \mathrm{D}$ porous electrode architecture. A larger interaction volume enables interfacial thin films of first-row transition-metal amorphous oxides and other non-crystalline materials with relatively low- $Z$ constituent atoms to be characterized by HEXS, and without the requirement for a micro-focused $\mathrm{X}$-ray beam. We study amorphous cobalt-containing thin films formed by anodic electrochemical deposition from dilute cobalt nitrate solutions in the presence of phosphate or borate as the electrolyte anion (Kanan \& Nocera, 2008; Surendranath et al., 2009). The corresponding amorphous $\mathrm{CoO}_{x}-\mathrm{Pi}$ and $\mathrm{CoO}_{x}$ - $\mathrm{Bi}$ thin films have been widely investigated as wateroxidizing catalysts for photoelectrochemical device (artificial leaf) applications (Nocera, 2012; Liu et al., 2016; GonzálezFlores et al., 2015; Risch et al., 2015). The amorphous domain for $\mathrm{CoO}_{x}$-Pi and $\mathrm{CoO}_{x}$-Bi share a common edge-sharing $O_{h}$ $\mathrm{CoO}_{6}$ cobaltate core (Farrow et al., 2013; Du et al., 2012; Kwon et al., 2015; Kanan et al., 2010; Risch et al., 2015, 2012) but differ in domain size. $\mathrm{CoO}_{x}$-Pi consists of small monolayer cobaltate domains, with $\sim 11 \AA$ maximum dimension (Du et al., 2012; Farrow et al., 2013), while $\mathrm{CoO}_{x}$-Bi shows larger, $\sim 20 \AA$, domains, with turbostratic disordered stacking of approximately three layers (Farrow et al., 2013; Kwon et al., 2015). $\mathrm{CoO}_{x}-\mathrm{Pi}$ and $\mathrm{CoO}_{x}$-Bi serve as useful reference materials for developing capabilities for PDF characterization of electrode-supported thin-film disordered and moleculardimensioned materials.

The described 3D porous working electrode (WE) improves the intensity of the scattered signal for thin films compared with a 2D planar WE design by a factor that scales with surface area. We demonstrate an electrode design consisting of a glass-capillary array (GCA) that is selectable with pore diameters in the $2 \mu \mathrm{m}$ to $100 \mu \mathrm{m}$ range, and is conformally coated with a transparent conductive oxide (TCO) using atomic layer deposition (ALD). This approach provides porous electrode architectures with surface chemistries that can be tuned to match those utilized in a range of electrochemical (Danilovic et al., 2014; Ocko et al., 1990; Tidswell et al., 1993; Ingham et al., 2008) and solar photoelectrochemical (Reece et al., 2011; Nocera, 2012) devices. With electrodes fabricated from GCAs with $40 \mu \mathrm{m}$-diameter pores and coated with either a $40 \mathrm{~nm}$ indium tin oxide (ITO) or a $50 \mathrm{~nm}-100 \mathrm{~nm}$ amorphous indium zinc oxide (a-IZO) layer (Lee et al., 2014), PDFs were readily obtained with $0.2 \AA$ spatial resolution for amorphous cobalt oxide water-oxidation catalyst films having thicknesses down to $60 \mathrm{~nm}$. This level of spatial resolution resolves the cobaltate domain size and structure, the presence of defect sites assigned to the domain edges (Kwon et al., 2015; Du et al., 2012) and the change in fine structure associated with redox state cycling, thereby enabling quantitative structurefunction understanding. High-resolution PDF measurements on films with thicknesses below $60 \mathrm{~nm}$ are also accessible by 
use of higher-surface-area substrates. The results suggest the opportunity to perform PDF structural analyses on monolayers of surface-bound molecular complexes by extending porous electrode designs to sub-micrometre scale pores.

\section{Experimental procedures}

\subsection{Electrode design and preparation}

We investigated a number of planar and 3D porous electrode architectures as WEs for in situ interrogation of amorphous thin films of first-row transition-metal oxides using HEXS measurements under controlled electrochemical conditions. Planar electrodes were ITO-coated, $180 \mathrm{~nm}$ thick, $\leq 10 \Omega$ per square, on polished glass and precision cut to $3 \mathrm{~mm}$ $\times 10 \mathrm{~mm} \times 1.1 \mathrm{~mm}$ (Präzisions Glas \& Optik GmbH). A 3D electrode design that we found to be amenable to a broad range of electrochemical applications used a GCA plate wrapped with a TCO layer by ALD (Elam, Baker, Martinson et al., 2008; Lee et al., 2014).

An illustration of the TCO-coated GCA electrode assembly, TCO/GCA, is shown in Fig. 1. The borosilicate GCA has a $1.1 \mathrm{~mm}$ thickness with $40 \mu \mathrm{m}$ pores arrayed in a hexagonal honeycomb structure (58\% pore density), was purchased from InCom Inc, and cut into $2.4 \mathrm{~mm} \times 10 \mathrm{~mm}$ size. Conformal TCO coatings were produced with a commercial wafer-style reactor (Savannah 200, Cambridge Nanotech) at $100^{\circ} \mathrm{C}$ under low vacuum in flowing $\mathrm{N}_{2}$. In one version, a $32 \mathrm{~nm}$ layer of ITO was deposited as a crystalline conductive oxide by ALD in a process adapted from previous reports (Elam, Baker, Martinson et al., 2008; Elam et al., 2006; Elam, Baker, Hryn et al., 2008). Briefly, 20 super cycles of 10 cycles each (200 ALD cycles total) were run, with each super-cycle-dosing schedule consisting of: \{[cyclopentadienylindium(I)-soak $]$-purge-ozone-purge $\}_{8}+\{[$ tetrakis(dimethylamido)tin(IV)-soak]-purge-ozone-purge $\}$ with timing [(1-
$30)-30-60-25]_{8}-[(1-15)-30-60-25]$ in seconds at a temperature of $225^{\circ} \mathrm{C}$ with In and Sn precursors heated to $70^{\circ} \mathrm{C}$ and $55^{\circ} \mathrm{C}$, respectively. The relatively long 30 and $15 \mathrm{~s} \mathrm{soak}$ times are performed without pumping during and shortly after each metal organic precursor dose to ensure complete diffusion of the ALD precursors into the high-aspect-ratio substrates. In a second version, ALD of a $50 \mathrm{~nm}-100 \mathrm{~nm}$ IZO was used to provide an amorphous conductive oxide layer with a conductivity comparable to ITO. The ALD process was adapted from a previous report (Lee et al., 2014). Briefly, 200 super cycles of 10 ( $1 \mathrm{Zn}, 9$ In) cycles each (720 ALD cycles total) were run, with each super-cycle-dosing schedule consisting of: [(trimethylindium-soak )-purge-water-purge $]_{9}+$ [(diethylzinc-soak)-purge-ozone-purge] with timing [(1-5)$20-3-20]_{9}-[(1-5)-20-0.5-20]$ in seconds at a temperature of $220^{\circ} \mathrm{C}$. The relatively long five-second soak time is performed without pumping during and shortly after each metal organic precursor dose to ensure complete diffusion of the ALD precursor species, specifically, the In precursor on the $\mathrm{ZnO}_{x}$ surface and the $\mathrm{Zn}$ precursor on the $\mathrm{InO}_{x}$ surface during the ALD reaction cycles. Finally, the ITO- and IZO-coated porous electrodes were annealed at $400^{\circ} \mathrm{C}$ under flowing $\mathrm{N}_{2}$ for $1 \mathrm{~h}$ to improve the conductivity. An $\sim 80 \%$ ratio of indium to zinc in a-IZO films shows a low resistivity of $3.9 \times 10^{-4} \Omega \mathrm{cm}$ and high electron mobility, $>50 \mathrm{~cm}^{2} \mathrm{~V}^{-1} \mathrm{~s}^{-1}$, one of the highest among the reported ALD-grown transparent conducting oxides, while still avoiding crystallinity (Lee et al., 2014).

For both versions of the TCO/GCA electrode assembly, a gold thin film was deposited by thermal evaporation on one surface of the GCA prior to TCO deposition in order to reduce the sheet resistance (resistance to electrical conduction from the wire contact along the face of the membrane). A capillary-cutting stone (HR4-334, Hampton Research) was used to circumscribe a 'scratch' through the conductive layers, creating electrochemically active and inactive zones. The inactive side provided a scattering background for the $\mathrm{TCO} /$

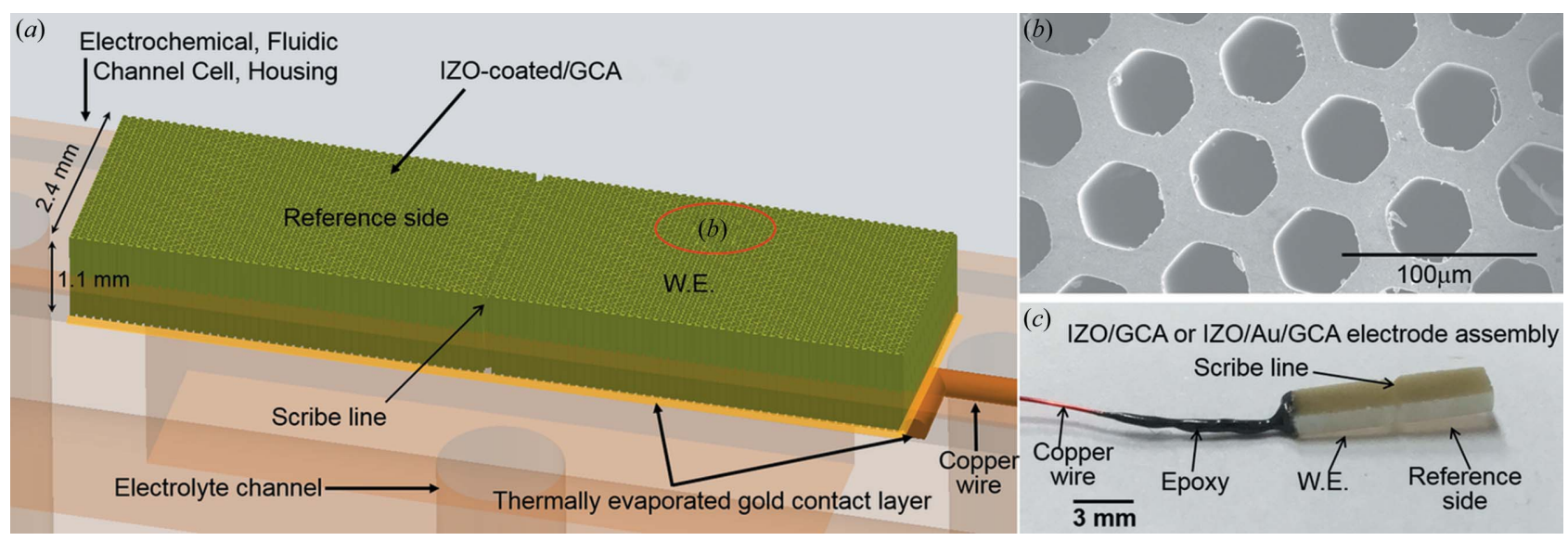

Figure 1

GCA electrode assembly. (a) Schematic diagram of the microporous electrode assembly, composed of a $50 \mathrm{~nm}$-thick IZO-coated $2.4 \mathrm{~mm} \times 1.1 \mathrm{~mm} \times$ $10 \mathrm{~mm}$ GCA with $40 \mu \mathrm{m}$ pores, IZO/Au/GCA. The bottom surface was further coated with a thermally evaporated Au (100 nm) layer that provided an efficient electrical contact. The scribe line shown in parts $(a)$ and $(c)$ separates the electrical connection between the WE and scattering reference sides. (b) Picture of the $40 \mathrm{~mm}$ porous IZO/GCA. (c) Image of the experimental IZO/Au/GCA electrode assembly, viewed from the side with the electricalcontacting copper wire. The epoxy seal of the contact region shown in $(c)$ is not illustrated in $(a)$ for better visualization. 
GCA electrode assemblies during operando electrochemical measurements. Figs. 1(b) and 1(c) show scanning electron and optical micrographs, respectively, of the $1.1 \mathrm{~mm} \times 2.4 \mathrm{~mm} \times$ $10 \mathrm{~mm}$ (height $\times$ width $\times$ length) electrode assembly.

\subsection{Beamline electrochemical cell}

Fig. 2(a) shows a computer-aided design (CAD) of the in situ electrochemical module holding a microporous WE used for HEXS measurements. The custom 3D-printed electrochemical cell includes an electrolyte reservoir, and the electrochemical compartment, housing the porous WE, a reference electrode (RE) and a counter electrode (CE). The cell connects to tubing which forces electrolyte flow through the porous electrode via a syringe pump. The reusable cell was fabricated with a 3D printer (Objet30 Pro, Stratasys Ltd) using optically transparent VeroClear-RGD810 (Stratasys Ltd) that permits visible inspection of the inside of the cell during electrolysis or X-ray scattering. Prior to assembly, the printed in situ cell was sonicated in a solution of $0.5 \mathrm{M} \mathrm{NaOH}$ solution in deionized water and then rinsed using deionized water. This process was repeated several times to remove low-cross-linked support materials on the surface of the printed cell.

The WE was connected with polyurethane/nylon insulated copper wire (8056, BELDEN). Silver paste (\#12642-14, Electron Microscopy Science) was used to contact the IZO-coated/ $\mathrm{Au} / \mathrm{GCA} W E$ to the copper wire and the assembly was dried in an oven. Chemical-resistant epoxy (9340, Loctite) was applied to cover the silver paste and exposed copper wire. A silver/ silver chloride $(\mathrm{Ag} / \mathrm{AgCl}) \mathrm{RE}$ was constructed from a glass tube [VitroCom, \#CV2024, $2.0 \mathrm{~mm}$ inner diameter (ID) $\times$ $2.4 \mathrm{~mm}$ OD (outer diameter)], a porous Teflon frit $(\mathrm{CH}$ Instruments Inc., product ID: CHI_RETIP), and silverchloride film deposition on silver wire (CHE112, CH Instruments Inc.) performed at $0.5 \mathrm{~V}$ versus normal hydrogen electrode (NHE) in $0.1 M$ hydrochloric acid solution for $30 \mathrm{~min}$. The RE was positioned adjacent to the $\mathrm{WE}$, as shown in Fig. 2(b). A Pt wire, shown in Fig. 2(a), was used as a CE. A $25 \mu$ m-thick polyimide film (Kapton, Lebow Company) shown in yellow in Figs. 2(b) and 2(c) serves as an X-ray transmissive window and is sealed with chemical-resistant epoxy (LOCTITE 9340, McMaster-Carr). The in situ cell was mounted on a kinematic base (BKL-4, Newport), a dovetail optical rail (RLA0600, THORLABS) and a rail carrier (RC1, THORLABS). A syringe was primed to remove bubbles through the entire cell and tubing. The syringe pump was then mounted on a programmable bidirectional syringe pump (NE1010, New Era Pump Systems Inc.), which was connected to the electrochemical cell body through phthalate-free TYGON tubing (Saint-Gobain SE-200, 1/8 inch OD, Fisher Scientific) in a position that provided a continuous electrolyte flow through the porous WE by a pre-programmed schedule. Flowing electrolyte through the porous electrode helped to clear oxygen bubbles formed on the WE during oxygen-evolving catalysis as well as replenishing electrolyte in the pores of the WE.

\subsection{Solution preparation and film growth}

Detailed information about the preparation of the electrolyte and electrochemical deposition of amorphous cobalt oxide water-splitting catalysts films in the presence of borate $\left(\mathrm{CoO}_{x}-\mathrm{Bi}\right)$ and phosphate $\left(\mathrm{CoO}_{x}-\mathrm{Pi}\right)$ has been previously reported (Kanan \& Nocera, 2008; Risch et al., 2012; Du et al., 2012). For $\mathrm{CoO}_{\mathrm{x}}-\mathrm{Bi}$, thin films were deposited onto the planar ITO glass or microporous IZO-coated GCA from electrolyte solutions containing $0.1 \mathrm{M}$ borate, $\mathrm{pH} 9.0$, and $0.5 \mathrm{mM}$ $\mathrm{Co}\left(\mathrm{NO}_{3}\right)_{2} \cdot 6 \mathrm{H}_{2} \mathrm{O}$ (Strem Chemical Inc.), as described previously (Kwon et al., 2015). A potentiostat (Epsilon, Bioanalytical Systems Inc.) was used to perform all of the

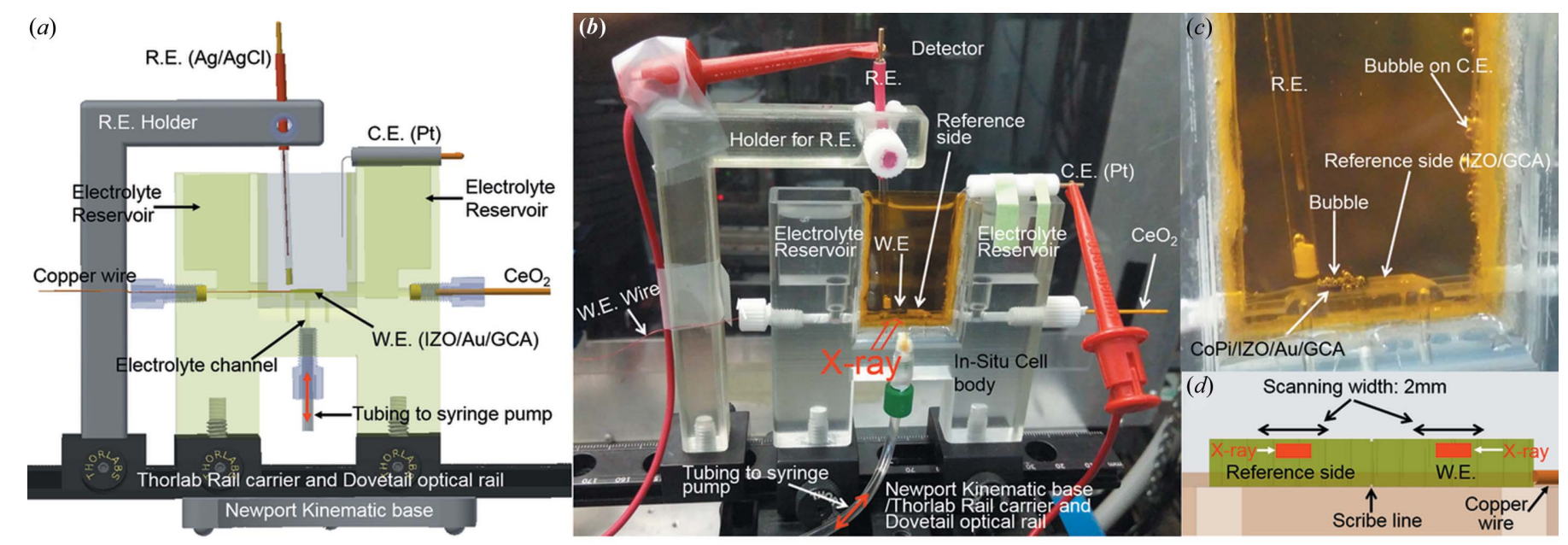

Figure 2

(a) CAD of the in situ electrochemical cell. (b) A photograph of the in situ electrochemical cell assembly installed during HEXS data acquisition and consisting of electrolyte reservoir, in situ cell body with syringe pump, WE, RE, CE, holder for RE, and mounting stage including Newport Kinematic base, Thorlab rail carrier and dovetail optical rail. Polyimide film (yellow) holds electrolyte. (c) Magnification of the WE and reference side during electrolysis after $1 \mathrm{~h}$ of electrolysis. (d) Scaled, schematic side-view drawing showing the horizontal scanning width of X-ray on IZO/Au/GCA electrode. The size of the incoming X-ray beam is $500 \mathrm{~mm}$ (width) by $300 \mathrm{~mm}$ (height) as indicated by the red rectangular box in $(d)$. 
three-electrode experiments. $I$ (current) $\times R$ (resistance) compensation was not included in any of the electrochemical measurements. For $\mathrm{CoO}_{x} \mathrm{Pi}$ catalyst deposition, electrolyte solutions of $0.1 \mathrm{M}$ potassium phosphate (KPi, $\mathrm{pH} 7.0$ ) containing $0.5 \mathrm{~m} M \mathrm{Co}\left(\mathrm{NO}_{3}\right)_{2} \cdot 6 \mathrm{H}_{2} \mathrm{O}(93-2746$, Strem Chemical Inc.) were prepared from potassium phosphate $\left(\mathrm{KPi}, \mathrm{KH}_{2} \mathrm{PO}_{4}\right.$, P5655 at Sigma-Aldrich) with ultra-pure water $(18.2 \mathrm{M} \Omega \mathrm{cm}$, MilliQ). The $\mathrm{pH}$ of the electrolyte solution was adjusted using concentrated potassium hydroxide (484016, Sigma-Aldrich) solution. Electrodeposition of $\mathrm{CoO}_{x}-\mathrm{Pi}$ film on planar ITO glass for the PDF measurements of $\mathrm{CoO}_{x}$-Pi by grazing incidence in the supported film and from ex situ powders were performed at $1.34 \mathrm{~V}$ versus NHE. Measurements of electrochemical potential-dependent PDF fine-structure changes were performed after a thick $\mathrm{CoO}_{x}$-Pi film was formed $(1 \mathrm{~h}$ at $1.34 \mathrm{~V}$ versus NHE) and then three sets of HEXS data with 5 min signal acquisitions at $0.5 \mathrm{~V}$ and $1.34 \mathrm{~V}$ versus NHE were obtained and finally averaged for PDF analysis. The experiment is described further below. For powder X-ray scattering measurements, $\mathrm{CoO}_{x}-\mathrm{Pi}$ and $\mathrm{CoO}_{x}$-Bi were scraped off $25 \mathrm{~cm}^{2}$ planar ITO electrode surfaces, collected as powders and placed in $0.7 \mathrm{~mm}$ borosilicate glass-capillary tubing (Friedrich \& Dimmock Inc.) for HEXS measurements.

\subsection{X-ray data acquisition and processing}

HEXS 2D scattering images, using $58.7 \mathrm{keV}$ (11ID-B, $\lambda=0.2114 \AA$ ) and $100.3 \mathrm{keV}$ (6ID-D, $\lambda=0.1236 \AA$ ) X-ray energies, were acquired at the Advanced Photon Source (APS) at the Argonne National Laboratory using a PerkinElmer amorphous silicon detector (Chupas et al., 2003, 2007). Sample-to-detector distances of $19 \mathrm{~cm}$ and $34 \mathrm{~cm}$ were used for the $58.7 \mathrm{keV}$ (beamline 11-ID-D) and $100.3 \mathrm{keV}$ (beamline 6-ID-D) measurements, respectively, and both were calibrated using a $\mathrm{CeO}_{2}$ powder pattern. The maximum $q$ value accessible in these measurements was $q_{\max }=4 \pi \sin (2 \theta / 2) / \lambda=$ $24 \AA^{-1}$ at $58.7 \mathrm{keV}$, where $2 \theta$ is the scattering angle and $\lambda$ is the $\mathrm{X}$-ray wavelength. 2D X-ray scattering patterns were integrated to a $1 \mathrm{D}$ spectrum using Fit $2 D$ software (Hammersley et al., 1996). X-ray data were acquired using a $300 \mu \mathrm{m}$ height $\times 500 \mu \mathrm{m}$ width beam profile and with $2 \mathrm{~mm}$ horizontal translation of the electrochemical cell as shown in Fig. 2(d). The movement of the electrochemical cell during the $\mathrm{X}$-ray data acquisition was used to provide spatial averaging. Both electrochemically active and inactive areas of the TCO/ GCA were interrogated during the time course of the electrochemical experiments, with the latter serving as the HEXS background. The X-ray interrogated areas are illustrated by the side-view diagram in Fig. 2(d). Background-scattering patterns of electrolyte/WE were subtracted from the sample scattering patterns of catalyst/electrolyte/WE, and corrected for X-ray polarization, sample absorption and Compton scattering using the PDFget X2 program (Qiu et al., 2004). The details of background subtraction have been previously described (Du et al., 2012).

$\mathrm{X}$-ray scattering measurements for $\mathrm{CoO}_{x}$ - $\mathrm{Bi}$ thin films supported on planar $3 \mathrm{~mm} \times 10 \mathrm{~mm} \times 1.1 \mathrm{~mm}$ ITO glass electrode (Präzisions Glas \& Optik GmbH) surfaces were measured at beamline 11-ID-D using a $23 \mathrm{keV}$ X-ray beam vertically focused to $15 \mu \mathrm{m}$ with a $0.3 \mathrm{~m}$ toroidal mirror. Different $\mathrm{CoO}_{x}$-Bi coated ITO electrodes were prepared having a $\mathrm{CoO}_{x}$ - $\mathrm{Bi}$ layer thickness that varied from $0.5 \mu \mathrm{m}$ to $2 \mu \mathrm{m}$ (Kwon et al., 2015) controlled by the electrolysis time. Following electrolysis, $\mathrm{CoO}_{x}-\mathrm{Bi}$ coated ITO glass electrodes were removed from the film-forming electrochemical cell, rinsed with distilled water and air dried. The ITO electrode surface was aligned parallel to the incident X-ray beam and positioned to traverse the $3 \mathrm{~mm}$ electrode dimension. Scattering patterns were measured on a Pilatus $2 \mathrm{M}$ detector (beamline 11-ID-D). Detector images were azimuthally averaged and corrected for angle-dependent X-ray absorption. For positioning the $\mathrm{CoO}_{\mathrm{x}}$ - $\mathrm{Bi}$ coated ITO electrode in the X-ray beam, the electrode assembly was vertically scanned in $5 \mu \mathrm{m}$ steps while monitoring the X-ray scattering image. As the $\mathrm{CoO}_{x}$ - $\mathrm{Bi} / \mathrm{ITO} /$ glass electrode assembly progressed into the $\mathrm{X}$-ray probe, position-dependent contributions from air, $\mathrm{CoO}_{x}$-Bi, ITO and glass could be discerned. A vertical position of the electrode was chosen to maximize the contribution from the amorphous $\mathrm{CoO}_{x}$-Bi layer compared with the crystalline ITO and glass support.

\section{Results and discussion}

$\mathrm{X}$-ray scattering for an $\sim 1 \mu \mathrm{m}$-thick $\mathrm{CoO}_{x}$-Bi film supported on a planar ITO glass electrode in air is shown in Fig. 3(a), interrogated using an $\sim 15 \mu \mathrm{m}$ vertically focused $23 \mathrm{keV}$ X-ray beam with grazing incidence parallel to the ITO glass surface, in which the maximum scattering angle, $2 \theta_{\max }$, was $74^{\circ}$ with a $q_{\text {max }}$ of $13 \AA^{-1}$. The scattering geometry is shown diagrammatically in Fig. 3(b). The parallel incidence scattering for the electrode-supported $\mathrm{CoO}_{x}$-Bi film in Fig. 3(a) is compared in this same $q$-range with a high-resolution HEXS pattern $(59 \mathrm{keV})$ for a comparable $\mathrm{CoO}_{\mathrm{x}}-\mathrm{Bi}$ film that had been scraped off the ITO surface and measured as an ex situ powder (Kwon et al., 2015). Overall, the electrode-supported film measured by grazing-incidence and ex situ powder-scattering patterns showed good agreement in the $q$-range below $9 \AA^{-1}$. Above this $q$ value, deviations were seen that presumably reflect inhomogeneities arising from edge effects and distortions because of an acute angle of incidence of the scattered $\mathrm{X}$-rays on the mosaic detector. We found that the grazingincidence geometry was limited by two factors. First, the inability to extract high-quality scattering patterns for films with thicknesses below $0.5 \mu \mathrm{m}$ because of the small fraction of the $15 \mu \mathrm{m}$ focused X-ray beam that interacts with the thin film. This limitation was prohibitively severe when an electrolyte overlayer needed for in situ electrochemical measurements was added to the assembly. Second, the $q_{\max }$ attainable with a $23 \mathrm{keV}$ beam restricts spatial resolution to about $0.48 \AA$. The thin-film limit could be addressed by the use of a sub-micrometre-focused X-ray beam, but the combination of a submicrometre vertically focused high-energy ( $>50 \mathrm{keV}) \mathrm{X}$-ray beam would be needed to achieve high-spatial-resolution PDFs on interfacial 2D ultra-thin films. However, sub-micro- 


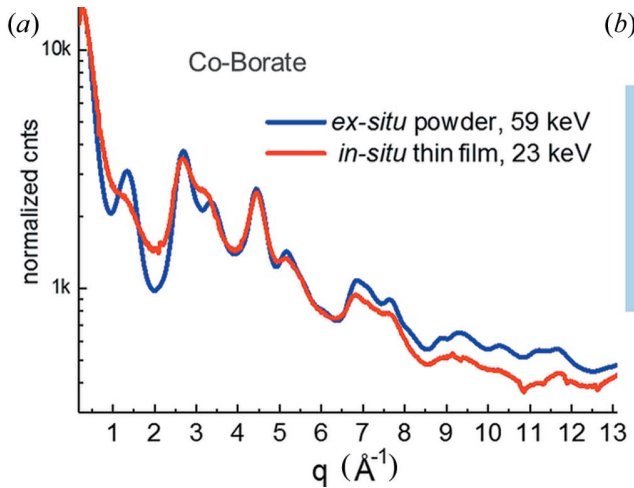

(b)

Figure 3

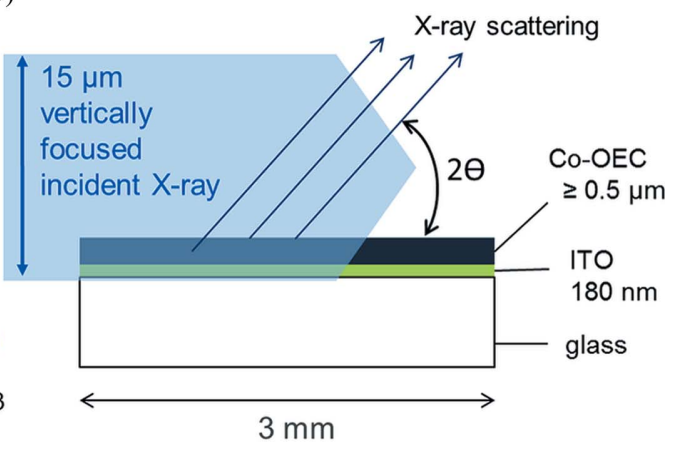

(a) Comparison of scattering patterns for the $\mathrm{CoO}_{x}$-Bi thin-film catalyst. The red line trace shows the scattering pattern measured as an $\sim 1 \mu \mathrm{m}$ film supported on a planar ITO glass electrode in air using a $3 \mathrm{~mm}$ sample film path length with the grazing-incidence geometry sketched in part (b). The blue line trace shows a portion of the $59 \mathrm{keV}$ scattering pattern measured for the $\mathrm{CoO}_{x}$-Bi powder sample in a $1 \mathrm{~mm}$-diameter polyimide tube. (b) Grazingincidence scattering geometry used for ITO-supported $\mathrm{CoO}_{x}$-Bi OEC thin-film measurements, using an $\sim 15 \mu \mathrm{m}$ vertically focused $23 \mathrm{keV} \mathrm{X}$-ray beam.

metre-focused high-energy X-ray beams are not currently available at the APS.

In order to enable PDF analyses of interfacial films with thickness below $0.5 \mu \mathrm{m}$ and in the presence of electrolyte needed for operando measurements, we designed a microporous, high-surface-area electrode architecture that allows utilization of unfocused high-energy X-ray beams. We demonstrate this approach using a TCO-coated GCA. The electrochemical properties of an ITO/GCA assembly with $40 \mu \mathrm{m}$ pores are shown in Fig. 4. Cyclic voltammograms (CVs) for the $\mathrm{CoO}_{x}$-Pi OEC on planar ITO/glass WE as a reference, Fig. 4(a), are compared with those measured for the ITO/GCA WE, Fig. 4(b). CVs were recorded at time points during continuous $\mathrm{CoO}_{x}$-Pi electrochemical deposition and film growth with $1.05 \mathrm{~V}$ (NHE) applied potential from an aqueous electrolyte solution containing $0.5 \mathrm{mM} \mathrm{Co}\left(\mathrm{NO}_{3}\right)_{2} \cdot 6 \mathrm{H}_{2} \mathrm{O}$ and $0.1 M \mathrm{KPi}, \mathrm{pH} 7.0$ (Kanan \& Nocera, 2008; Surendranath et al., 2009). On the first anodic sweep with a fresh ITO electrode, a peak is seen at $1.1 \mathrm{~V}$ (NHE) corresponding to the oxidation of the $\mathrm{Co}$ (II) solution and deposition of the $\mathrm{Co}$ (III) oxide, followed by a catalytic onset at $1.23 \mathrm{~V}$ (Kanan \& Nocera, 2008; Surendranath et al., 2009). With continuous electrolysis, the
$\mathrm{CoO}_{x}$-Pi film thickens, and the anodic sweeps show plateau peaks that arise from the $\mathrm{Co}(+3 /+2)$ redox couple and the insulator-to-semiconductor transition in the $\mathrm{CoO}_{x}-\mathrm{Pi}$ film (Costentin et al., 2016; Surendranath et al., 2010; Risch et al., 2012, 2015; Klingan et al., 2014; González-Flores et al., 2015). Corresponding electrochemical features are seen in the CVs with the ITO/GCA WE, although the electrochemical transitions are broadened and slightly shifted, apparently because of increased series resistance and capacitance in the microporous electrode assembly. Comparable CVs were measured for both the ITO/GCA and IZO/GCA assemblies. Causes for the differences between planar and microporous TCO as WEs for CV measurements are not fully understood. Preliminary experiments suggest that the distortions in the CVs for the microporous compared with the planar TCO WEs cannot be recovered by increasing the ALD TCO layer thickness beyond the $50 \mathrm{~nm}-150 \mathrm{~nm}$ dimensions which are used for the in situ X-ray measurements described below. This suggests the possibility that contributions from electrochemically active surface sites may differ between the planar and microporous TCO electrode geometries. This aspect is being further investigated. At present, the TCO coatings described here are
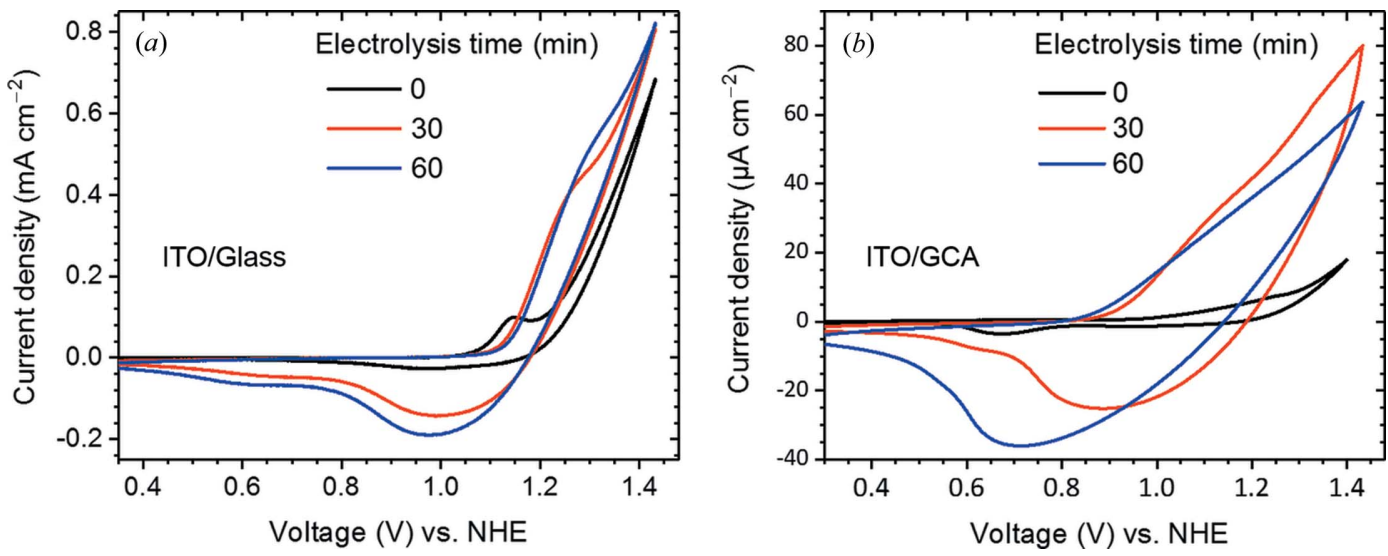

Figure 4

Comparison of cyclic voltammetric curves for planar ITO/glass $(a)$, and ITO/Au/40 $\mu \mathrm{m}$ GCA $(b)$ WEs in an electrolyte that contained $0.1 M$ phosphate, $\mathrm{pH} 7.0$, and $0.5 \mathrm{mM} \mathrm{Co}\left(\mathrm{NO}_{3}\right)_{2} \cdot 6 \mathrm{H}_{2} \mathrm{O}$. CV traces were recorded using $5 \mathrm{mV} \mathrm{s}^{-1}$ scan rates, and following 0 min, 30 min and 60 min of otherwise continuous electrolysis at $1.34 \mathrm{~V}$ (versus NHE). 
noted to allow adequate electrochemical control of the electrode and catalyst potential while also providing, as described below, an X-ray scattering background compatible with highresolution operando PDF measurements.

Figs. 5(a) and 5(b) show scanning electron micrographs of an ITO/GCA WE after a $4 \mathrm{~h} \mathrm{CoO}_{x}$-Pi catalyst-film electrochemical deposition within the porous electrode. Upon drying, the $\mathrm{CoO}_{x}$-Pi film contracts allowing film to separate from the ITO pore surface. This results in the formation of the observed free-standing, pore-templated, tubular-shaped $\mathrm{CoO}_{x}$ films. The uniformity of tube-wall thickness along the length of each
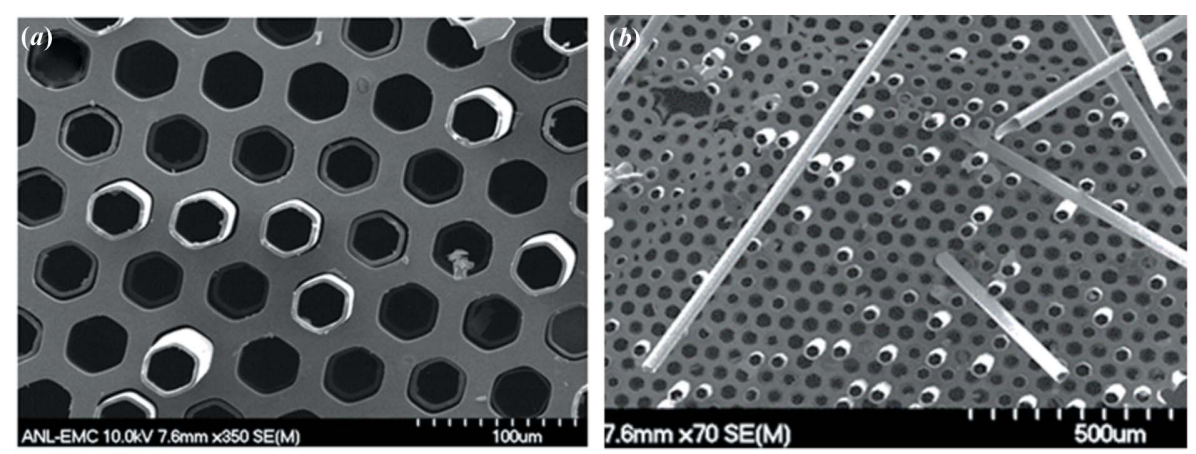

(c)

(d)
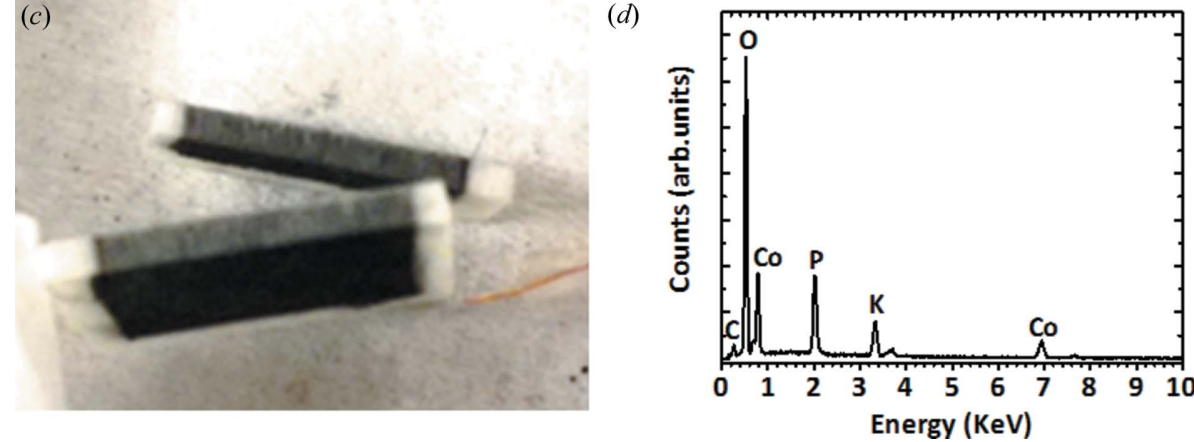

Figure 5

(a) SEM image of the electrodeposited $\mathrm{CoO}_{x}$-Pi catalyst film electrochemically deposited onto the ITO/GCA electrode support. (b) SEM expanded view showing uniform $\mathrm{CoO}_{x}-\mathrm{Pi}$ 'tubes' removed from the templating electrode pores. (c) Optical micrograph of the ITO/GCA electrode assembly supporting the electrochemically deposited $\mathrm{CoO}_{x}$-Pi thin-film catalyst, split in half, exposing the interior transverse pores. (d) EDX plot acquired at $12 \mathrm{kV}$. Carbon, oxygen, phosphorous and potassium originated from $K \alpha$. Co at $6.929 \mathrm{keV}$ and at $0.776 \mathrm{keV}$ originated from $K \alpha$ and $K \beta$, respectively. tube suggests that the ITO/GCA supports uniform electrochemistry throughout the length of each pore. The uniformity of the catalyst-film coating is also demonstrated by visual inspection of a cleaved ITO/GCA after electrolytic $\mathrm{CoO}_{x}-\mathrm{Pi}$ deposition, Fig. 5(c). Elemental composition analysis by energy-dispersive X-ray (EDX), Fig. 5(d), shows the composition and Co:P:K ratio of 3:1:0.7 of the catalyst film to be comparable with those measured from the $\mathrm{CoO}_{x}$-Pi catalyst deposited on planar ITO electrode surfaces (Kanan \& Nocera, 2008). The uniformity of the electrochemical film deposition along the $1.1 \mathrm{~mm}$ GCA pore dimensions easily accommodates the cross section of an unfocused highenergy synchrotron beam, highlighting the opportunity to use these microporous supports for in situ PDF analysis of thin-film catalysts.

To demonstrate this capability, HEXS patterns measured for $\mathrm{CoO}_{x}-\mathrm{Bi}$ and $\mathrm{CoO}_{x}-\mathrm{Pi}$ as in situ ITO/GCA supported films in the absence of electrolyte are shown in Figs. 6(a) and $6(b)$, respectively, and are compared with PDF patterns measured for corresponding samples that were electrolytically grown on planar ITO electrodes and scraped off and examined as ex situ powders (Du et al., 2012; Kwon et al., 2015; Farrow et al., 2013). Powder samples removed from planar electrode surfaces currently serve as the samples of choice for high-resolution PDF measurements of transition metal oxide catalyst films. Fig. 6 reveals the equivalence of the HEXS patterns for powder and in situ films throughout the experimental $q$-range, demonstrating the capability to make highresolution measurements on catalyst films in situ.

Figure 6
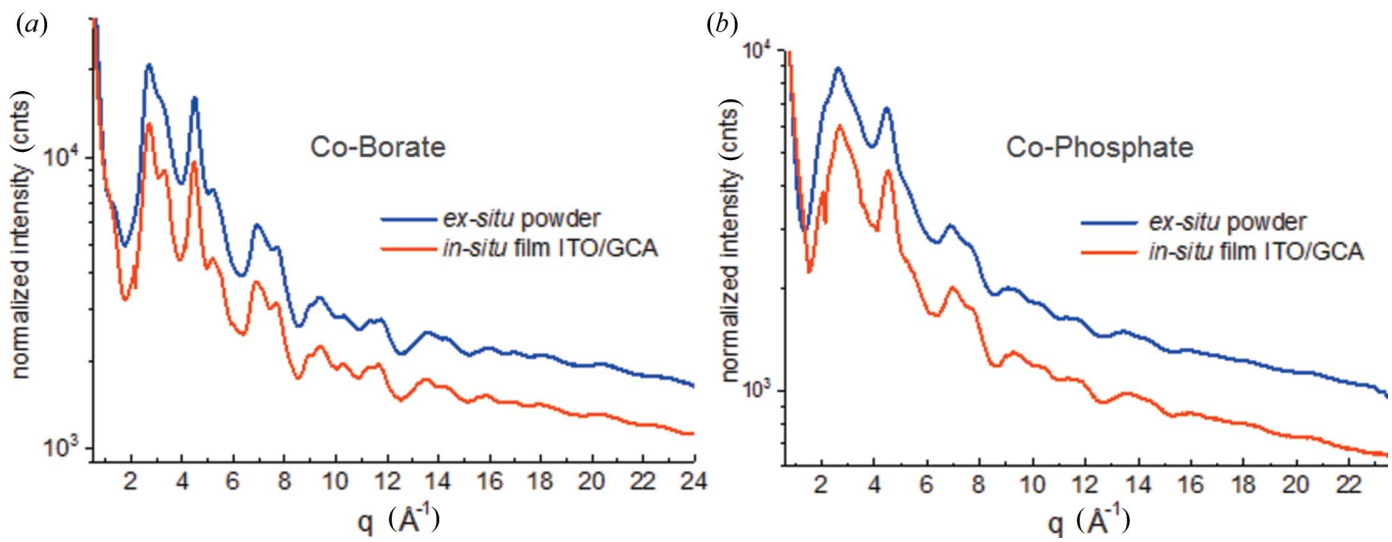

Comparison of HEXS (59 keV) patterns for $(a) \mathrm{CoO}_{x}$ - $\mathrm{Bi}$ and $(b) \mathrm{CoO}_{x}$-Pi measured as ITO/GCA supported films (red traces) and as powder samples (blue traces) scraped from planar ITO electrodes and collected in $1 \mathrm{~mm}$-diameter polyimide tubes. 

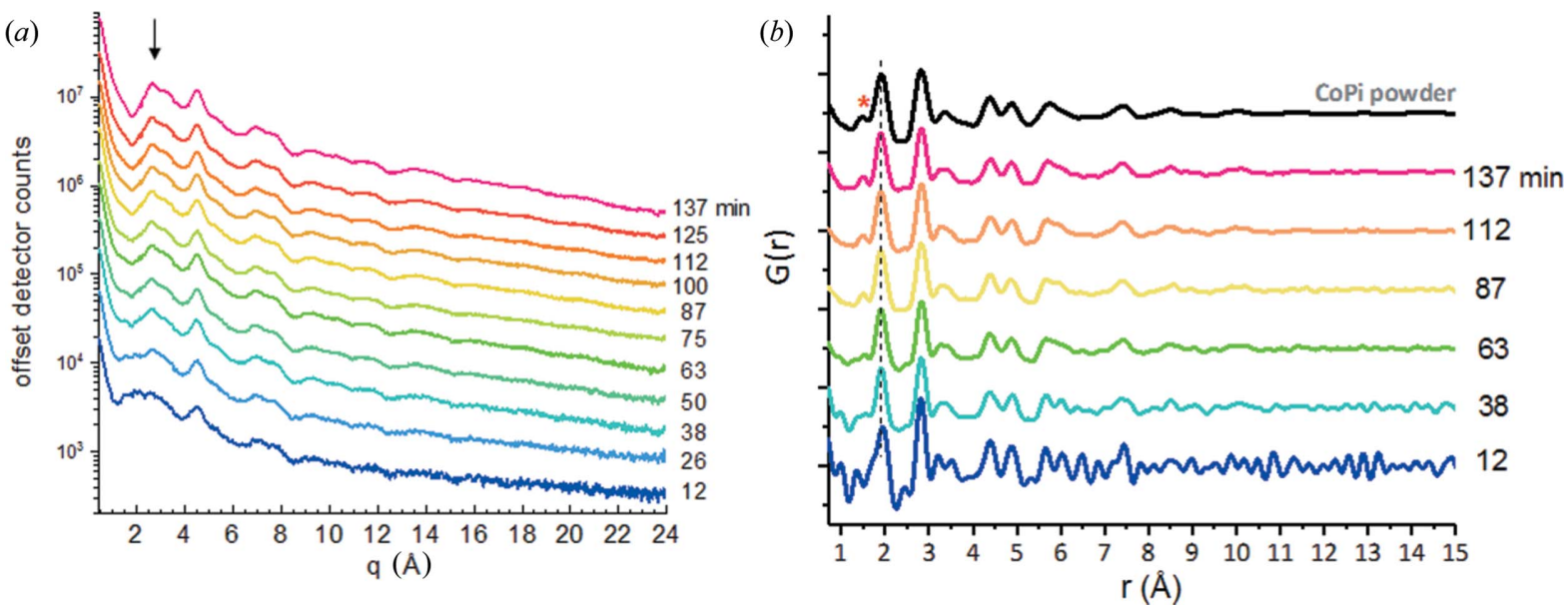

Figure 7

In situ X-ray monitoring of $\mathrm{CoO}_{x}$-Pi OEC during film growth on an ITO/GCA WE with $40 \mu \mathrm{m}$ pores. (a) Background-subtracted [electrolyte-filled reference area as indicated in Fig. 2(d)] HEXS data. HEXS patterns were collected with 2 min integration times at selected time points during continuous electrolytic $\mathrm{CoO}_{x}$-Pi film deposition from an electrolyte solution containing $0.1 M$ potassium phosphate, $\mathrm{pH} 7.0$, and $0.5 \mathrm{~m} M \mathrm{Co}\left(\mathrm{NO}_{3}\right)_{2} \cdot 6 \mathrm{H}_{2} \mathrm{O}$ with $1.85 \mathrm{~V}$ (versus NHE) applied potential. The X-ray beam was defined by $0.1 \mathrm{~mm}$ horizontal and $0.5 \mathrm{~mm}$ vertical slit apertures. $(b) G(r)$ Fourier transforms from the HEXS data in $(a)$. The top trace shows the $G(r)$ of $\mathrm{CoO}_{x}$-Pi powder as a reference for comparison. Noise in the HEXS patterns was attenuated using a 24-point smoothing function in the program PDFgetX2 (Qiu et al., 2004) prior to Fourier transform. The smoothing only partially removes Fourier ripple artifacts in the ensuing PDF. The high-frequency noise in the reciprocal-space data converts to non-physical pair correlations below $0.7 \AA$ (not shown). Longer acquisition times beyond the 2 min scans used in $(a)$ would be needed to raise the signal-to-noise and avoid these artifacts for thin $\mathrm{CoO}_{x}$-Pi films with electrolysis times shorter than $38 \mathrm{~min}$.

The ability to use the TCO/GCA WE for operando PDF analyses in an electrochemical cell is demonstrated in Fig. 7(a), which shows HEXS patterns measured with 2 min acquisition times sampled at various points during the time course of continuous electrolysis and $\mathrm{CoO}_{x}$-Pi film deposition at $1.85 \mathrm{~V}$ versus NHE. We note that compared with the HEXS measurements for the ITO/GCA supported films in air, Fig. 5, the operando measurements shown in Fig. 7 include the presence of flowing electrolyte in the GCA pores. An additional benefit of the microporous GCA with approximate $64 \%$ porosity is that it restricts the electrolyte contribution to background scattering. TCO/GCA background-subtracted HEXS, Fig. 7(a), and corresponding PDF patterns, Fig. 7(b), demonstrate the opportunity to utilize the TCO/GCA to track real-time deposition, growth and structural evolution of amorphous $\mathrm{CoO}_{x}-\mathrm{Pi}$ catalyst thin films. The HEXS and PDF patterns for supported films derived from the operando HEXS data are quite similar to those of the ex situ powder samples (Kwon et al., 2015), although there is evidence for time evolution in the fine features of these scattering signals. Interestingly, the position of the PDF peak at $1.95 \AA$, arising from the first coordination shell $\mathrm{Co}-\mathrm{O}$ distance (Du et al., 2012), is shifted $\sim 0.04 \AA$ toward a longer radial distance in the early 12 min time point compared with later traces, as seen in Fig. 7(b). This bond-distance increase is consistent with the presence of lower-valence cobalt in the thinnest films, which is more like the $\mathrm{Co}^{2+}$ species in the electrodeposition solution. The 12 min HEXS pattern shows a broadening of low- $q$ features compared with later traces, marked by the arrow in Fig. 7(a). The PDF in Fig. 7(b) also suggests structural evolution in the detection of the phosphorous-oxygen bond distance peak at $1.50 \AA$ (marked by the asterisk) over time. The signal-to-noise in the 12 min time-point trace is limited by the single image, 2 min acquisition time. Improvements in signal-to-noise for a thin-film sample can be achieved by taking averages of the repeated single time point or by extending the integration time.

For comparison, Fig. 8 shows difference HEXS patterns $\left(\mathrm{CoO}_{x}\right.$-Bi/ITO/GCA - ITO/GCA) measured with $4.5 \mathrm{~min}$ integration time recorded at $5 \mathrm{~min}$ intervals during an analogous $\mathrm{CoO}_{x}$-Bi OEC film deposition with continuous electrolysis from a circulating electrolyte solution that contained $0.1 M$ potassium borate, $\mathrm{pH} 9.2$, and $0.5 \mathrm{mM} \mathrm{Co}\left(\mathrm{NO}_{3}\right)_{2} \cdot 6 \mathrm{H}_{2} \mathrm{O}$ with $1.4 \mathrm{~V}$ (NHE) applied potential. The initially deposited film shows a pattern of scattering peaks, for example marked at $q=2.43 \AA^{-1}, 4.10 \AA^{-1}$ and $6.31 \AA^{-1}$, on an amorphous scattering background. During $\mathrm{CoO}_{x}$-Bi film growth, the scattering patterns show continuous progression that reflect a characteristic evolution in $\mathrm{CoO}_{x}$ - $\mathrm{Bi}$ OEC film structure. A detailed analysis of time-dependent changes in $\mathrm{CoO}_{x}-\mathrm{Pi}$ and $\mathrm{CoO}_{x}$-Bi OEC film structures during electrochemical deposition will be presented elsewhere. Here we highlight these results to demonstrate the TCO/CGA as a WE design that has general applicability for operando structural characterization of first-row transition-metal thin films using HEXS and PDF analyses. The high surface area of these electrodes compensates for the low-scattering cross-sections with high-energy $\mathrm{X}$-rays.

An assessment of sensitivity for operando HEXS measurements was made by comparison of HEXS amplitudes to film-thickness estimates made from scanning electron microscopy (SEM), Fig. 9. Fig. 9(a) shows a plot of scattering intensities measured for the peak of the $\mathrm{CoO}_{x}-\mathrm{Pi}$ at $q=$ $4.5 \AA^{-1}$ as a function of film-deposition time, using the timesequence dataset shown in Fig. 7(a). The data were collected at two positions along the pore channels. The first position was 


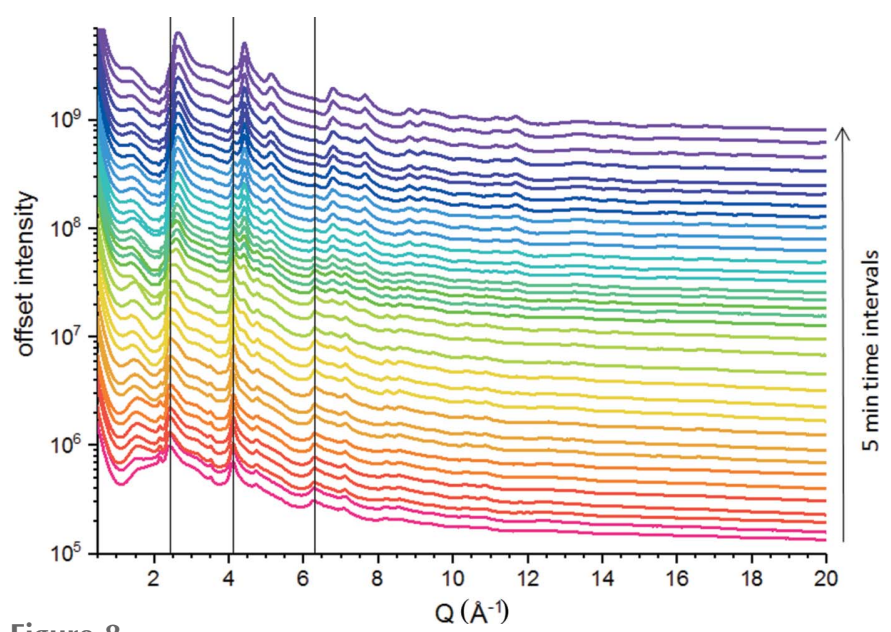

Figure 8

In situ X-ray monitoring of $\mathrm{CoO}_{x}$-Bi OEC during film growth on an ITO/ GCA WE with $40 \mu \mathrm{m}$ pores. The traces show background-subtracted [electrolyte-filled reference area as indicated in Fig. 2(d)] HEXS patterns collected with $4.5 \mathrm{~min}$ integration at $5 \mathrm{~min}$ time intervals during continuous electrolytic $\mathrm{CoO}_{\mathrm{x}}$-Bi film deposition from an electrolyte solution containing $0.1 \mathrm{M}$ potassium borate, $\mathrm{pH} 9.2$, and $0.5 \mathrm{mM}$ $\mathrm{Co}\left(\mathrm{NO}_{3}\right)_{2} \cdot 6 \mathrm{H}_{2} \mathrm{O}$ with $1.4 \mathrm{~V}$ (versus NHE) applied potential. For reference, the vertical lines mark the positions of the scattering peaks at $q=2.43 \AA^{-1}, q=4.10 \AA^{-1}$ and $q=6.31 \AA^{-1}$ as seen in the first HEXS pattern. HEXS patterns were shifted vertically by multiplication for clarity. The X-ray beam was defined by $0.1 \mathrm{~mm}$ horizontal and $0.5 \mathrm{~mm}$ vertical slit apertures.

approximately $50 \mu \mathrm{m}$ below the top surface of the TCO/GCA assembly, the second shifted $100 \mu \mathrm{m}$ along the pore direction below this. The results show the linearity of film electrodeposition with time, and the uniformity of film deposition along the pore axis. In a separate equivalent ITO/GCA electrode, a parallel $\mathrm{CoO}_{x}$ - $\mathrm{Pi}$ electrochemical deposition was run for $50 \mathrm{~min}$, stopped, rinsed with water, dried and used for SEM analysis. Fig. 9(b) shows the resulting SEM images for this electrode. Portions of the $\mathrm{CoO}_{x}$-Pi film are seen to detach from the pore wall upon drying in vacuum. From these spots, the thickness of the $\mathrm{CoO}_{x}$-Pi film can be seen in cross section, and measured to be about $400 \mathrm{~nm}$-thick after $50 \mathrm{~min}$ of electrolysis. This permits an approximate film-thickness scaling, as shown by the right-hand axis in the time-dependent in situ $\mathrm{CoO}_{x}$-Pi deposition in Fig. 9(a). The calibration shows that the $40 \mu \mathrm{m}$ pore $\mathrm{TCO} / \mathrm{GCA}$ provides a sensitivity sufficient to detect HEXS for amorphous $\mathrm{CoO}_{x}-\mathrm{Pi}$ films with $60 \mathrm{~nm}$ thickness.

The film-thickness sensitivity in these operando experiments is primarily set by the volume fractions of the electrolyte and the GCA support within the TCO/GCA assembly. The TCO layer makes only a small volume contribution. For example, for the ITO/GCA assembly used in Figs. 7-9, the GCA was composed of hexagonally packed, $40 \mu \mathrm{m}$ diameter, rounded hexagonal-shaped pores with a $50 \mu \mathrm{m}$ center-tocenter pore spacing. From this we estimate the volume fractions of the electrolyte-filled pore, GCA support, $40 \mathrm{~nm}$ ITO coating and $60 \mathrm{~nm} \mathrm{CoO}_{x}$-Pi film within the WE assembly to be $0.633,0.360,0.003$ and 0.004 , respectively. Adjustments to the TCO layer thickness in the $40 \mathrm{~nm}$ to $150 \mathrm{~nm}$ range cause only a small variation in the volume contribution because of the $\mathrm{CoO}_{x}$ film, and in all cases the limiting $60 \mathrm{~nm}$ film thickness can be estimated to have an $\sim 0.4 \%$ volume contribution under operando conditions. The experimental data are consistent with this estimate. For example, the ITO/GCA subtracted scattering signal from the $\mathrm{CoO}_{x}$-Pi supported film $\mathrm{WE}$ at the $12 \mathrm{~min}$ time point in Figs. 7 and $9(a)$ had 3236 detector counts during the 2 min acquisition time measured for the peak at $q=4.5 \AA^{-1}$, which was $0.33 \%$ of the total scattering signal. At higher angle, $q=20 \AA^{-1}$, the $\mathrm{CoO}_{x}$-Pi film scattering signal diminished to 421 counts, representing $0.1 \%$ of the total operando WE scattering. Our experiments with ALD coatings with GCAs having different diameters show that HEXS signals for thin films scale with the porous electrode surface area. Based on these considerations, we anticipate that a strategy for accomplishing PDF analyses of sub-
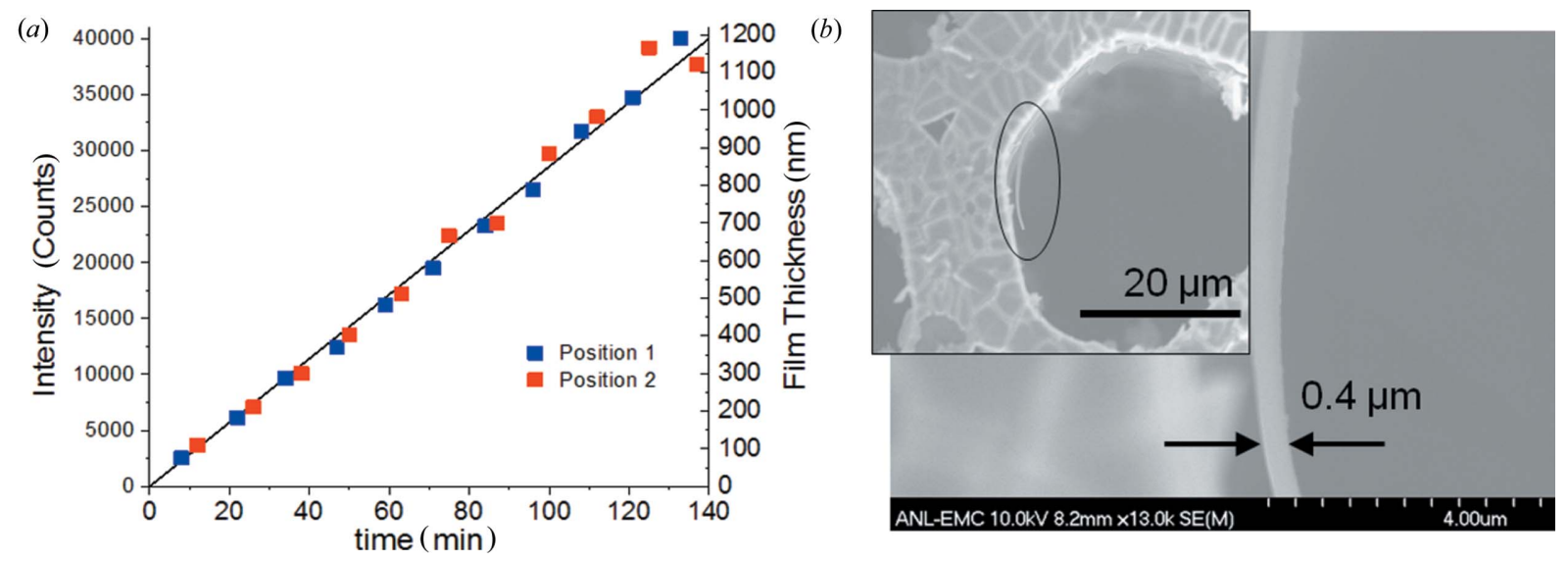

Figure 9

Time-dependent in situ measurement of $\mathrm{CoO}_{x}$-Pi electrochemical film deposition. (a) Plot of HEXS signal intensity at selected times during the continuous electrochemical deposition, as described in Fig. 7. The scattering intensity was measured by the amplitude of the peak feature at $q=4.5 \AA^{-1}$ and recorded for two positions along the ITO/GCA pore. The first position was placed just below the top edge of the ITO/GCA, the second $0.1 \mathrm{~mm}$ below this spot, shown as blue and red symbols, respectively. The X-ray beam was defined by $0.1 \mathrm{~mm}$ horizontal and $0.5 \mathrm{~mm}$ vertical slit apertures. (b) SEM image of $\mathrm{CoO}_{x}$-Pi film on the ITO/GCA electrode following $50 \mathrm{~min}$ of electrolysis, using the conditions described in Fig. 7. The inset shows a field-of-view imaging of one of the ITO/GCA pores. The circle marks the area of enlargement shown on the right. 
nanometre supported films could be achieved by diminishing the volume contributions of the pore-filled electrolyte and porous support. We note that porous anodic alumina oxide (AAO) membranes offer one such assembly (Elam et al., 2003, 2006). For example, we estimate that an AAO membrane with $50 \%$ porosity and $20 \mathrm{~nm}$ TCO-coated $200 \mathrm{~nm}$ pores would provide a WE with over 100-fold higher surface area than the $40 \mu \mathrm{m} \mathrm{ITO/GCA} \mathrm{assemblies} \mathrm{used} \mathrm{here,} \mathrm{and} \mathrm{offer} \mathrm{the} \mathrm{oppor-}$ tunity to extend the PDF analyses of sub-nanometre films.

Finally, we found the TCO/GCA to be a suitable WE for in situ electrochemical fine-structure analysis by operando HEXS. For example, Fig. 10 shows PDF patterns measured for a $\mathrm{CoO}_{\mathrm{x}}$-Pi OEC film that was cycled between electrochemical potentials of $0.5 \mathrm{~V}, 1.0 \mathrm{~V}$ and $1.5 \mathrm{~V}$ (versus NHE), corresponding to electrochemical regimes where the di- $\mu$-oxolinked cobalt pairs are considered to be in the $\mathrm{Co}(+3 /+2)$, $\mathrm{Co}(+3 /+3)$ and $\mathrm{Co}[($ mixture: $+3,+4) /+3]$ oxidation states, respectively (Costentin et al., 2016; Surendranath et al., 2010; Risch et al., 2012, 2015; Klingan et al., 2014; González-Flores et al., 2015). The $\mathrm{CoO}_{x}$-Pi was first grown on an IZO/GCA electrode for $60 \mathrm{~min}$ by electrolysis at $1.34 \mathrm{~V}$ (versus NHE) in $0.1 M$ phosphate, $\mathrm{pH} 7.0$, and $0.5 \mathrm{~m} M \mathrm{Co}\left(\mathrm{NO}_{3}\right)_{2} \cdot 6 \mathrm{H}_{2} \mathrm{O}$. Fig. 10 compares PDF patterns measured at $0.5 \mathrm{~V}$ and $1.0 \mathrm{~V}$. The PDF patterns correspond to the 13 cobaltate atom domain model described previously, in which each of the PDF peaks can be correlated with atom-pair distances in the domain model (Du

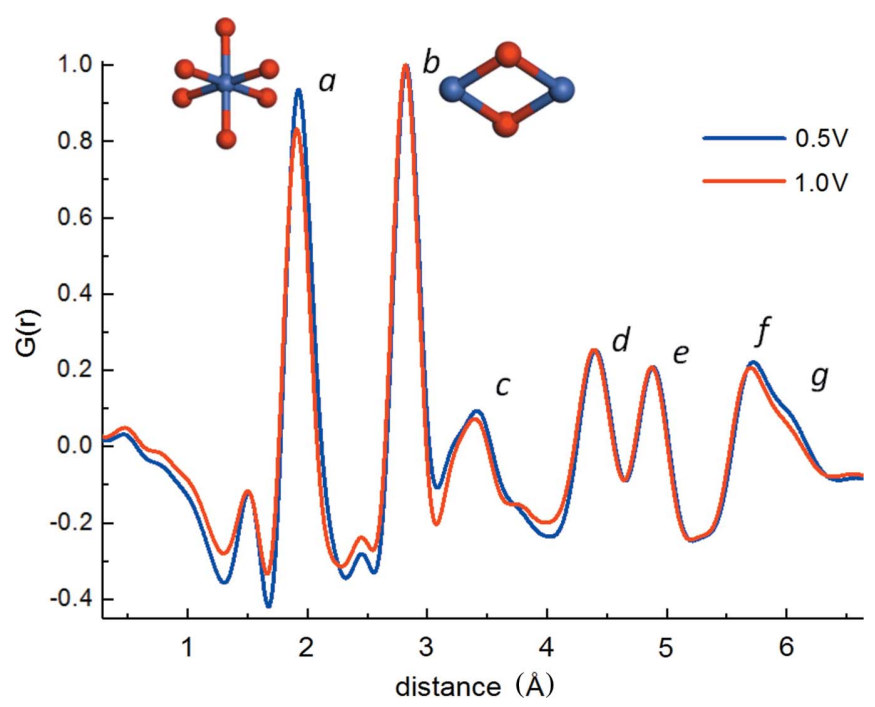

Figure 10

Operando PDF analysis for the $\mathrm{CoO}_{x}$-Pi OEC, resolving the change in fine structure associated with redox state cycling between 0.5 and $1.34 \mathrm{~V}$ (versus NHE). A $\mathrm{CoO}_{x}$-Pi OEC was grown on an IZO/GCA WE by $60 \mathrm{~min}$ electrolysis at $1.34 \mathrm{~V}$ (versus NHE) in $0.1 M$ phosphate, $\mathrm{pH} 7.0$, and $0.5 \mathrm{~m} M \mathrm{Co}\left(\mathrm{NO}_{3}\right)_{2} \cdot 6 \mathrm{H}_{2} \mathrm{O}$. Subsequently, HEXS and PDF patterns were measured as a function of applied potential that was cycled between $0.5 \mathrm{~V}, 1.0 \mathrm{~V}$ and $1.5 \mathrm{~V}$ (versus NHE). The figure compares PDF patterns measured at $0.5 \mathrm{~V}$ and $1.0 \mathrm{~V}$ in the blue and red line traces, respectively. The peaks labeled $a$ through to $g$ correspond to atom-pair distances that are characteristic of the cobaltate domain structure (Du et al., 2012; Kwon et al., 2015). For example, the peak $a$ is associated with the first-shell Co$\mathrm{O}$ ligand distances, and peak $b$ corresponds to the $\mathrm{Co}-\mathrm{Co}$ distance across the di- $\mu$-oxo bond. Illustrative structures are inserted next to each of these peaks. The cobalt and oxygen atoms are colored blue and red, respectively. et al., 2012; Farrow et al., 2013; Kwon et al., 2015). Peaks labeled $a, c$ and $g$ correspond to $\mathrm{Co}-\mathrm{O}$ atom pairs that include terminal oxygen atoms at the domain edge. The shortest $\mathrm{Co}-\mathrm{O}$ peak, $a$, arises from the first-shell ligand bonding distance. Peaks $b, d, e$ and $f$ correspond to Co-Co atom pairs, with peak $b$ arising from the distance between di- $\mu$-oxo-linked cobalt atoms (Du et al., 2012; Farrow et al., 2013; Kwon et al., 2015). Starting from a potential of $0.5 \mathrm{~V}$, an increase in the oxidation potential to $1 \mathrm{~V}$ is accompanied by a slight atom-pair distance shortening, seen in a $0.02 \AA$ shift in the position of peak $a$, which is consistent with the oxidation of some of the cobalt centers in the domain and is comparable with results from extended XAFS measurements (Risch et al., 2015). Detectable too are slight changes to the amplitudes of peaks $a, c$ and $g$ that include $\mathrm{Co}-\mathrm{O}$ atom pairs involving terminal oxygen atoms. In contrast, the peaks $b, d, e$ and $f$ associated with Co-Co atom pairs in the domain lattice show no amplitude alteration. We interpret these results as supporting a model in which redox activity is localized at the domain edges, and is associated with a disordering of terminal oxo coordination geometries. The PDF fine-structure changes are seen to be reproducible upon cycling between $0.5 \mathrm{~V}, 1.0 \mathrm{~V}$ and $1.5 \mathrm{~V}$. An increase in potential from $1.0 \mathrm{~V}$ to $1.5 \mathrm{~V}$ produces no additional changes in PDF features. A more complete analysis and discussion of redoxstate-dependent fine-structure changes in Co-oxide OEC thin films will be presented and discussed elsewhere. However, here we use these results to demonstrate the opportunity to use the TCO/GCA as a robust, high-surface-area WE for electrochemical-based PDF structure analyses of catalytic thin films by HEXS.

\section{Conclusion}

Operando PDF analysis via HEXS of high-surface-area electrodes enables the first opportunity to detect structure and structural evolution during the growth of electrochemically deposited films. The new experimental design further affords the opportunity to resolve structure as a function of an applied potential under water-oxidation conditions for catalytic thin films with thicknesses that range from $60 \mathrm{~nm}$ to micrometre scales. The TCO/GCA electrode design successfully addresses three technical challenges for high-sensitivity HEXS measurements. Specifically, the design: (i) provides a high surface area that is needed to compensate for low X-ray scattering cross-section by high-energy $X$-rays when interrogating thin films composed of low- $Z$ atoms, (ii) limits the electrolyte volume and therefore the contribution to background scattering, and (iii) delivers an amorphous silica template and nanoscale TCO coating by ALD with minimal HEXS background. A custom 3D-printed electrochemical cell was shown to allow precise and reproducible arrangement of the three-electrode setup. Finally, the results demonstrate the opportunity to combine advances in high-surface-area porous materials and ALD to produce tunable substrates for interfacial PDF analyses. The scalability of the interfacial PDF measurement to pore size and surface area suggests the opportunity to extend the interfacial catalyst analysis to the 
molecular scale by using porous supports with sub-micrometre pore dimensions.

\section{Acknowledgements}

GK gratefully acknowledges Michelle Givens, Brenda Davis, Neil Bartkowiak and Brian Rusthoven at the APS 3D print shop, and thanks Michael Wieczorek at the APS Fabrication of Crystal Optics/Chemical Etching shop.

\section{Funding information}

Work at the Argonne National Laboratory on water-splitting catalysis and PDF analyses of the cobalt oxide thin films was supported by the Division of Chemical Sciences, Geosciences, and Biosciences, Solar Photochemistry Program, Office of Basic Energy Sciences of the US Department of Energy (DOE) under Contract DE-AC02-06CH11357. Development of porous electrode architectures with atomic layer deposition was supported initially by the Argonne Northwestern Solar Energy Research (ANSER) Center, and currently by the Center for Light Energy Activated Redox Processes (LEAP), an Energy Frontier Research Center funded by the US DOE, Office of Science and Office of Basic Energy Sciences under Award Number DE-SC0001059. High-energy X-ray scattering measurements were carried out at beamlines 11-ID-B, 6ID-D and 11ID-D of the Advanced Photon Source, an Office of Science User Facility operated for the US DOE Office of Science by the Argonne National Laboratory and supported by the US DOE under Contract No. DE-AC02-06CH11357. Use of the Center for Nanoscale Materials, an Office of Science user facility, was supported by the US Department of Energy, Office of Science, Office of Basic Energy Sciences, under Contract No. DE-AC02-06CH11357.

\section{References}

Billinge, S. J. L. \& Kanatzidis, M. G. (2004). Chem. Commun. p. 749. Billinge, S. J. L. \& Levin, I. (2007). Science, 316, 561-565.

Blakemore, J. D., Mara, M. W., Kushner-Lenhoff, M. N., Schley, N. D., Konezny, S. J., Rivalta, I., Negre, C. F. A., Snoeberger, R. C., Kokhan, O., Huang, J., Stickrath, A., Tran, L. A., Parr, M. L., Chen, L. X., Tiede, D. M., Batista, V. S., Crabtree, R. H. \& Brudvig, G. W. (2013). Inorg. Chem. 52, 1860-1871.

Borkiewicz, O. J., Shyam, B., Wiaderek, K. M., Kurtz, C., Chupas, P. J. \& Chapman, K. W. (2012). J. Appl. Cryst. 45, 1261-1269.

Borkiewicz, O. J., Wiaderek, K. M., Chupas, P. J. \& Chapman, K. W. (2015). J. Phys. Chem. Lett. 6, 2081-2085.

Chupas, P. J., Chapman, K. W., Chen, H. L. \& Grey, C. P. (2009). Catal. Today, 145, 213-219.

Chupas, P. J., Chapman, K. W. \& Lee, P. L. (2007). J. Appl. Cryst. 40, 463-470.

Chupas, P. J., Qiu, X., Hanson, J. C., Lee, P. L., Grey, C. P. \& Billinge, S. J. L. (2003). J. Appl. Cryst. 36, 1342-1347.

Costentin, C., Porter, T. R. \& Savéant, J.-M. (2016). J. Am. Chem. Soc. 138, 5615-5622.

Danilovic, N., Subbaraman, R., Chang, K.-C., Chang, S. H., Kang, Y. J., Snyder, J., Paulikas, A. P., Strmcnik, D., Kim, Y.-T., Myers, D., Stamenkovic, V. R. \& Markovic, N. M. (2014). J. Phys. Chem. Lett. 5, 2474-2478.

Dippel, A.-C., Roelsgaard, M., Boettger, U., Schneller, T., Gutowski, O. \& Ruett, U. (2019). IUCrJ, 6, 290-298.
Du, P., Kokhan, O., Chapman, K. W., Chupas, P. J. \& Tiede, D. M. (2012). J. Am. Chem. Soc. 134, 11096-11099.

Elam, J. W., Baker, D. A., Hryn, A. J., Martinson, A. B. F., Pellin, M. J. \& Hupp, J. T. (2008). J. Vac. Sci. Technol. A, 26, 244-252.

Elam, J. W., Baker, D. A., Martinson, A. B. F., Pellin, M. J. \& Hupp, J. T. (2008). J. Phys. Chem. C, 112, 1938-1945.

Elam, J. W., Martinson, A. B. F., Pellin, M. J. \& Hupp, J. T. (2006). Chem. Mater. 18, 3571-3578.

Elam, J. W., Routkevitch, D., Mardilovich, P. P. \& George, S. M. (2003). Chem. Mater. 15, 3507-3517.

Farrow, C. L., Bediako, D. K., Surendranath, Y., Nocera, D. G. \& Billinge, S. J. L. (2013). J. Am. Chem. Soc. 135, 6403-6406.

González-Flores, D., Sánchez, I., Zaharieva, I., Klingan, K., Heidkamp, J., Chernev, P., Menezes, P. W., Driess, M., Dau, H. \& Montero, M. L. (2015). Angew. Chem. Int. Ed. 54, 2472-2476.

Hammersley, A. P., Svensson, S. O., Hanfland, M., Fitch, A. N. \& Hausermann, D. (1996). High. Press. Res. 14, 235-248.

Ingham, B., Illy, B. N., Toney, M. F., Howdyshell, M. L. \& Ryan, M. P. (2008). J. Phys. Chem. C, 112, 14863-14866.

Jensen, K. M. Ø., Blichfeld, A. B., Bauers, S. R., Wood, S. R., Dooryhée, E., Johnson, D. C., Iversen, B. B. \& Billinge, S. J. L. (2015). IUCrJ, 2, 481-489.

Juhás, P., Cherba, D. M., Duxbury, P. M., Punch, W. F. \& Billinge, S. J. L. (2006). Nature, 440, 655-658.

Jung, H., Allan, P. K., Hu, Y.-Y., Borkiewicz, O. J., Wang, X.-L., Han, W.-Q., Du, L.-S., Pickard, C. J., Chupas, P. J., Chapman, K. W., Morris, A. J. \& Grey, C. P. (2015). Chem. Mater. 27, 1031-1041.

Kanan, M. W. \& Nocera, D. G. (2008). Science, 321, 1072-1075.

Kanan, M. W., Yano, J., Surendranath, Y., Dincă, M., Yachandra, V. K. \& Nocera, D. G. (2010). J. Am. Chem. Soc. 132, 13692-13701.

Klingan, K., Ringleb, F., Zaharieva, I., Heidkamp, J., Chernev, P., Gonzalez-Flores, D., Risch, M., Fischer, A. \& Dau, H. (2014). ChemSusChem, 7, 1301-1310.

Koop, T., Schindler, W., Kazimirov, A., Scherb, G., Zegenhagen, J., Schulz, T., Feidenhans'l, R. \& Kirschner, J. (1998). Rev. Sci. Instrum. 69, 1840-1843.

Kordesch, M. E. \& Hoffman, R. W. (1984). Nucl. Instrum. Methods Phys. Res. 222, 347-350.

Kwon, G., Kokhan, O., Han, A., Chapman, K. W., Chupas, P. J., Du, P. \& Tiede, D. M. (2015). Acta Cryst. B71, 713-721.

Lee, D.-J., Kwon, J.-Y., Kim, J., Kim, K.-J., Cho, Y.-H., Cho, S.-Y., Kim, S.-H., Xu, J. \& Kim, K.-B. (2014). J. Phys. Chem. C, 118, 408-415.

Liu, C., Colón, B. C., Ziesack, M., Silver, P. A. \& Nocera, D. G. (2016). Science, 352, 1210-1213.

Merte, L. R., Behafarid, F., Miller, D. J., Friebel, D., Cho, S., Mbuga, F., Sokaras, D., Alonso-Mori, R., Weng, T.-C., Nordlund, D., Nilsson, A. \& Roldan Cuenya, B. (2012). ACS Catal. 2, 2371-2376.

Michel, F. M., Ehm, L., Antao, S. M., Lee, P. L., Chupas, P. J., Liu, G., Strongin, D. R., Schoonen, M. A. A., Phillips, B. L. \& Parise, J. B. (2007). Science, 316, 1726-1729.

Morcrette, M., Chabre, Y., Vaughan, G., Amatucci, G., Leriche, J. B., Patoux, S., Masquelier, C. \& Tarascon, J. M. (2002). Electrochim. Acta, 47, 3137-3149.

Mulfort, K. L., Mukherjee, A., Kokhan, O., Du, P. W. \& Tiede, D. M. (2013). Chem. Soc. Rev. 42, 2215-2227.

Németh, K., Chapman, K. W., Balasubramanian, M., Shyam, B., Chupas, P. J., Heald, S. M., Newville, M., Klingler, R. J., Winans, R. E., Almer, J. D., Sandi, G. \& Srajer, G. (2012). J. Chem. Phys. 136, 074105.

Nocera, D. G. (2012). Acc. Chem. Res. 45, 767-776.

Ocko, B. M., Wang, J., Davenport, A. \& Isaacs, H. (1990). Phys. Rev. Lett. 65, 1466-1469.

Qiu, X., Thompson, J. W. \& Billinge, S. J. L. (2004). J. Appl. Cryst. 37, 678 .

Reece, S. Y., Hamel, J. A., Sung, K., Jarvi, T. D., Esswein, A. J., Pijpers, J. J. H. \& Nocera, D. G. (2011). Science, 334, 645-648.

Renner, F. U., Gründer, Y. \& Zegenhagen, J. (2007). Rev. Sci. Instrum. 78, 033903 . 
Risch, M., Klingan, K., Ringleb, F., Chernev, P., Zaharieva, I., Fischer, A. \& Dau, H. (2012). ChemSusChem, 5, 542-549.

Risch, M., Ringleb, F., Kohlhoff, M., Bogdanoff, P., Chernev, P., Zaharieva, I. \& Dau, H. (2015). Energy Environ. Sci. 8, 661674.

Robinson, K. M. \& O'Grady, W. E. (1993). Rev. Sci. Instrum. 64, 1061-1065.

Roelsgaard, M., Dippel, A.-C., Borup, K. A., Nielsen, I. G., Broge, N. L. N., Röh, J. T., Gutowski, O. \& Iversen, B. B. (2019). IUCrJ, 6, 299-304.

Surendranath, Y., Dincă, M. \& Nocera, D. G. (2009). J. Am. Chem. Soc. 131, 2615-2620.

Surendranath, Y., Kanan, M. W. \& Nocera, D. G. (2010). J. Am. Chem. Soc. 132, 16501-16509.

Tamura, K., Ocko, B. M., Wang, J. X. \& Adžić, R. R. (2002). J. Phys. Chem. B, 106, 3896-3901.
Tidswell, I. M., Marković, N. M., Lucas, C. A. \& Ross, P. N. (1993). Phys. Rev. B, 47, 16542-16553.

Veder, J.-P., Nafady, A., Clarke, G., Williams, R. P., De Marco, R. \& Bond, A. M. (2011). Electrochim. Acta, 56, 1546-1553.

Virtanen, S. (2002). Electrochim. Acta, 47, 3117-3125.

Wang, J., Ocko, B. M., Davenport, A. J. \& Isaacs, H. S. (1992). Phys. Rev. B, 46, 10321-10338.

Watanabe, N., Morais, J. \& Alves, M. C. M. (2007). J. Electron Spectrosc. Relat. Phenom. 156-158, 164-167.

Wiaderek, K. M., Borkiewicz, O. J., Castillo-Martínez, E., Robert, R., Pereira, N., Amatucci, G. G., Grey, C. P., Chupas, P. J. \& Chapman, K. W. (2013). J. Am. Chem. Soc. 135, 4070-4078.

Yang, K. R., Matula, A. J., Kwon, G., Hong, J., Sheehan, S. W., Thomsen, J. M., Brudvig, G. W., Crabtree, R. H., Tiede, D. M., Chen, L. X. \& Batista, V. S. (2016). J. Am. Chem. Soc. 138, 5511-5514. 